\title{
Biodiesel Production with Supercritical Ethanol Estimation using RBF-ANN Approach
}

\section{Hossein Rajabi-Kuyakhi* \\ Department of Chemical Engineering, University of Guilan, Iran}

*Corresponding author: Hossein Rajabi Kuyakhi, Department of Chemical Engineering, University of Guilan, Rasht 41996-13769, Iran, Tel: 989114142285;

Email: hosseinr1026@gmail.com

\section{Research Article \\ Volume 3 Issue 6}

Received Date: December 04, 2019

Published Date: December 23, 2019

DOI: $10.23880 /$ ppej-16000211

\section{Abstract}

Biodiesels as a renewable fuel can be an effective alternative for fossil fuels which can obtained from transesterification of triglycerides method. In this study, a radial basis function neural network (RBFNN) was employed to predict the biodiesel yield in supercritical ethanol solvent. The result obtained by RBFNN model was analyzed with the statistical parameters (i.e., MSE, MAAE\%, MEAE\%, RMSE and $\mathrm{R}^{2}$ ) and graphical method. The capability of RBFNN model was compared with the previous developed models. According the result obtained the RBFNN has the best performance with $\mathrm{R}^{2}=0.997, \mathrm{MSE}=0.00075$ and $\mathrm{RMSE}=0.0274$.

Keywords: Biodiesel; Radial basis function; Fossil fuels; Supercritical ethanol; Statistical parameters

\section{Introduction}

Today, search for suitable renewable energy is important due to global warming, environmental pollution, and depletion of world petroleum. Biodiesels as a renewable fuel can be an effective alternative for fossil fuels [1]. Biodiesels are derived from many sources such as vegetable oils, palm, soybean, rapeseeds, sunflower oils, animals' fats, and algae. Supercritical transesterification of triglycerides is an important method for producing the biodiesels [2,3]. The mathematical modeling of biodiesel production to estimate the effective parameters such as temperature, pressure, the molar ratio of reactant to oil and reaction time on biodiesel yield have complex analytical equations, costly and timeconsuming [2].
There aren't many investigations about the prediction of biodiesels yield in supercritical fluids such as ethanol yet. Recently, intelligence tools have been mostly used in many applications for data analyzing in many fields of oil and gas industry [4-7].

The main objective of this paper was to predicting the biodiesel yield using the radial basis function artificial neural network. To developed the model, four input values consisted of reaction temperature, pressure, time and oil-to-alcohol molar ratio, and one output, biodiesel yield, were considered.to evaluated the accuracy of the proposed model the statistical parameters (i.e., MSE, MAAE\%, MEAE\%, RMSE and $\mathrm{R}^{2}$ ) and graphical method such as William plot and relative deviation plot were employed. 


\section{Petroleum \& Petrochemical Engineering Journal}

\section{Radial Basis Function Neural Network (RBFNN)}

The radial basis function neural network (RBFNN) as a feed forward structure is consist of three main layers, an input layer, a nonlinear hidden layer and a linear output layer. There are common transfer functions such as spline, multi quadratic and Gaussian function may be used for hidden neurons $[8,9]$. The output of the $j^{\text {th }}$ hidden neuron to the input xk can be expressed as:

$$
\phi_{\mathrm{j}}\left(\mathrm{x}_{\mathrm{k}}\right)=\exp \left(-\frac{1}{\sigma_{\mathrm{j}}^{2}}\left\|\mathrm{x}_{\mathrm{k}}-\mathrm{u}_{\mathrm{j}}\right\|^{2}\right)
$$

Where $u_{j}$, is the centre vector for the $j^{\text {th }}$ hidden neuron, $\sigma_{j}$ is the spread of the Gaussian function and || || refer to the Euclidian norm The response of output layer is obtained by:

$$
\mathrm{y}_{\mathrm{i}}(\mathrm{x})=\sum_{\mathrm{j}=1}^{\mathrm{j}} \phi_{\mathrm{j}}(\mathrm{x}) \mathrm{w}_{\mathrm{j}}(\mathrm{x})(2)
$$

Where $w_{j}(x)$ is the output weight between the $j^{\text {th }}$ hidden neuron and the output neuron, $\mathrm{j}=1,2, \ldots, \mathrm{j} ; \mathrm{j}$ is the number of hidden neurons; $\varphi_{\mathrm{j}}(\mathrm{x})$ is the output of the of the jth $^{\text {th }}$ idden neuron (Table 1).

\begin{tabular}{|c|c|c|c|}
\hline Statistical Parameters & Train & Test & All data \\
\hline R2 & 0.996 & 0.999 & 0.997 \\
\hline MSE & $9.2 \mathrm{E}-05$ & 0.00023 & 0.00075 \\
\hline RMSE & 0.0303 & 0.015 & 0.0274 \\
\hline MEAE\% & 1.82 & 0.49 & 1.5 \\
\hline MAAE\% & 6.34 & 4.91 & 6.34 \\
\hline
\end{tabular}

Table 1: Statistical parameters of the developed model.

\section{Data Processing}

In this research, the data was collected using the supplied data in the work of Frapiccini and Marini [10]. The dataset were dividing into two parts for test and train data with 25 and 75 ratio percent respectively. The dataset was included reaction temperature, pressure, time and oil-to-alcohol molar ratio. The collected data were normalized between $(0,1)$ to improve the performance of the model by employing the following formula [11]:

$$
m_{i}=\frac{m-m_{\min }}{m_{\max }-m \min }
$$

Where mi is normalized data, $\mathrm{m}$ is original data, $\mathrm{n}$ min and $\mathrm{m}$ max are minimum and maximum of $\mathrm{m}$ data respectively.

\section{Result and Discussion}

The purpose of this article was the development of a radial basis function artificial neural network (RBFNN) with high accuracy to estimate the biodiesel yield in supercritical ethanol. As mentioned, 4 parameters were considered as input variable included reaction temperature, pressure, time and oil-to-alcohol molar ratio. To investigation the capability of the established model, the statistical parameters were employed (MSE, MAAE\%, MEAE\%, RMSE and $\mathrm{R}^{2}$ ) which obtained as following formulations $[12,13]$ :

$$
\begin{gathered}
M S E=\frac{\sum_{i=1}^{k}(a-e)^{2}}{k}(4) \\
R M S E=\sqrt{\frac{1}{k} \sum_{i=1}^{k}(a-e)^{2}}(5) \\
M E A E \%=\frac{1}{k} \sum_{i=1}^{k} \frac{|a-e|}{a} * 100(6) \\
M A A E \%=\frac{\max |e-a|}{a} * 100(7)
\end{gathered}
$$

Where $\mathrm{a}$ is actual value and $\mathrm{e}$ is estimated value.

The statistical parameters were measured and expressed in Table 1 by obtained result the RBFNN has good performance to estimating biodiesel yield in supercritical ethanol. Evaluation of predicted values verses experimental data are shown in Figure 1. The accumulation of data points near the $\mathrm{Y}=\mathrm{X}$ line verifies the performance of the RBFNN model. The network shows an acceptable performance for Train and Test data with $\mathrm{R}^{2}$ 0.996 and 0.999 respectively. The graphical method (relative deviation plot and William plot) was employed to evaluate the accuracy of the model. The relative deviation for both training and testing dataset has been computed and showed in Figure 2. The relative deviation values were obtained from equation $(8)[14,15]$. 


\section{Petroleum \& Petrochemical Engineering Journal}

$$
R D=\frac{e_{i}-a_{i}}{a_{i}}(8)
$$

Where RD is relative deviations, $\mathrm{e}_{\mathrm{i}}$ is estimated values and $a_{\mathrm{i}}$ is the actual value. The accumulation of relative values near the $Y=0$ line shows the appropriate performance of the RBFNN model.

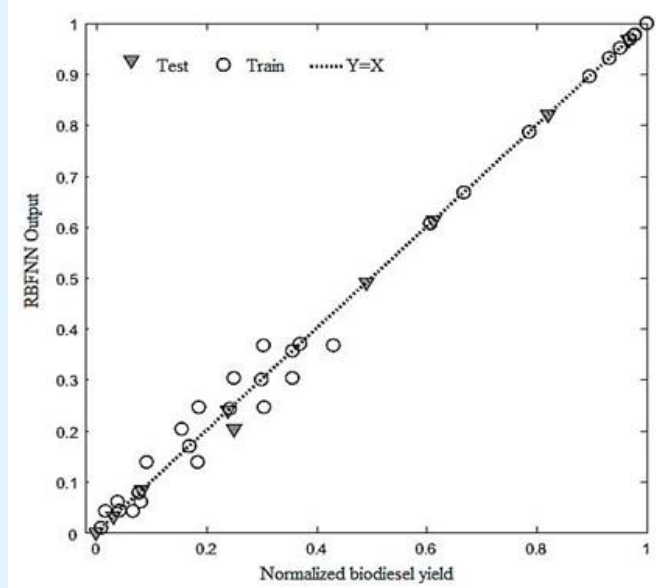

Figure 1: Regression analysis for test and train data.

Also applicability domain was used to evaluate the accuracy of the model. William plot was employed to this aim. This method generally used to distinguish between reliable and unreliable data point. The connection between estimated and observed values is obtained by the hat matrix $[16,17]$.

$$
H=X\left(X^{T} X\right)^{-1} X^{T}(9)
$$

Where $\mathrm{H}$ is symmetric matrix $\left(\mathrm{n}^{*} \mathrm{n}\right), \mathrm{X}$ is an $\left(\mathrm{m}^{*} \mathrm{n}\right)$ matrix which $\mathrm{m}$ is data point and $\mathrm{n}$ is number of parameter.
William plot is consisting of the standardized residuals in horizontal axes and HAT values in vertical axes. Critical leverage value $\left(\mathrm{H}^{*}\right)$ obtained from $3^{*}(\mathrm{p}+1) / \mathrm{n}$, where $\mathrm{p}$ is the number of parameters and $\mathrm{n}$ refer to the number of data point. The reliable values are located in $0 \leq \mathrm{H} \leq \mathrm{H}^{*}$ and between the standardized residual values $\pm 3[18,19]$. In Figure 3, as can be seen, the estimated values are in Applicability domain which shows the high accuracy of the model.

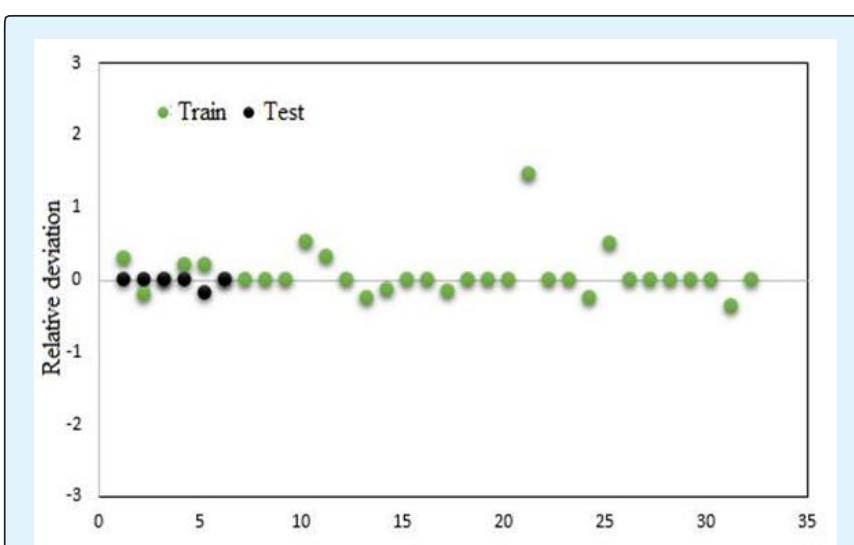

Figure 2: Relative deviation plots for test and train data.

In order to investigation the result of established model, the obtained results are compared to results of other published model in Table 2. As can be seen the RBFNN indicated the best performance for estimation of biodiesel yield against another intelligent algorithm. On the other hand, results from this comparison prove the better performance of RBFNN model for predicting the biodiesel yield.

\begin{tabular}{|c|c|c|c|c|c|c|c|}
\hline Temperature & Pressure(M Pa) & Time & $\mathbf{m} /$ oil & Exp & Farobie et al., [2]) & (Liu et al., [3]) & Present Model \\
\hline 270 & 20 & 5 & 40 & 0.043 & 0.0299 & 0.42061 & 0.04298 \\
\hline 270 & 20 & 15 & 40 & 0.132 & 0.1363 & 0.129361 & 0.1319 \\
\hline 300 & 20 & 5 & 40 & 0.0916 & 0.096 & 0.093241 & 0.0916 \\
\hline 300 & 20 & 25 & 40 & 0.5992 & 0.599 & 0.5934 & 0.5928 \\
\hline 350 & 20 & 15 & 40 & 0.7893 & 0.839 & 0.7885 & 0.7892 \\
\hline 350 & 20 & 25 & 40 & 0.9287 & 0.9282 & 0.92899 & 0.92865 \\
\hline 400 & 20 & 5 & 40 & 0.9129 & 0.9024 & 0.9111 & 0.9129 \\
\hline 400 & 20 & 20 & 40 & 0.9383 & 0.9287 & 0.9392 & 0.9382 \\
\hline 325 & 10 & 3 & 20 & 0.0291 & 0.0225 & 0.0301 & 0.0526 \\
\hline 325 & 10 & 15 & 20 & 0.161 & 0.157 & 0.1583 & 0.1623 \\
\hline
\end{tabular}

Table 2: comparison of the proposed algorithms and published approaches. 


\section{Petroleum \& Petrochemical Engineering Journal}

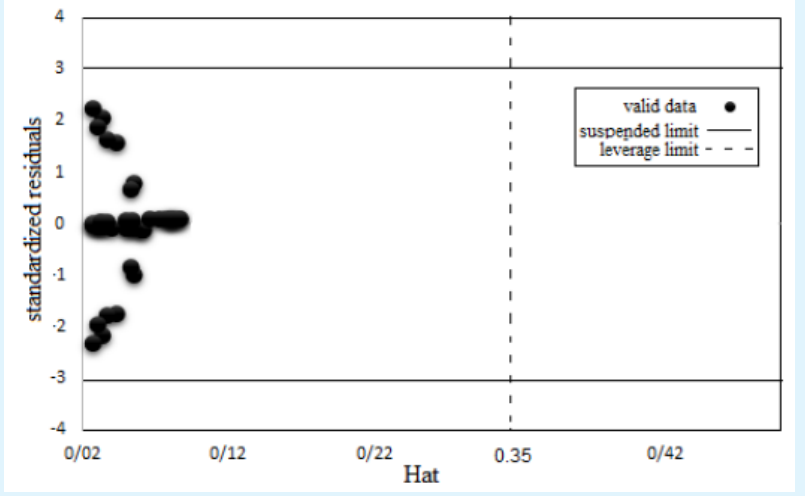

Figure 3: The Williams plot for the proposed predictive tool.

\section{Conclusion}

In this paper, the capability of RBFNN model was investigated to modeling to biodiesel yield in super critical ethanol solvent. The statistical parameters (i.e., MSE, RMSE, MAAE\%, MEAE\%, R ${ }^{2}$ ) and graphical method (i.e., William Plot and relative deviation) are used to evaluate the performance of the model. The results show the radial basis function neural network (RBFNN) has good performance for estimating of biodiesel yield with statistical parameters. (MSE $=0.000753$, RMSE $=0.0274$, MAAE $\%=6.34, \mathrm{MEAE} \%=1.5, \mathrm{R}^{2}=0.997$ ). According to the results, the RBFNN can be considered as a suitable tool for modeling the biodiesel yield in super critical ethanol solvent.

\section{References}

1. Srivastava A, Prasad R (2000) Triglyceridesbased diesel fuels. Renewable and Sustainable Energy Reviews 4(2): 111-133.

2. Farobie 0, Hasanah N, Matsumura YJP (2015) Artificial neural network modeling to predict biodiesel production in supercritical methanol and ethanol using spiral reactor. Procedia Environmental Sciences 28: 214-223.

3. Liu Z, Baghban AJES (2017) Application of LSSVM for biodiesel production using supercritical ethanol solvent. Energy Sources, Part A: Recovery, Utilization, and Environmental Effects 39(17): 1869-1874.
4. Baghban A, Namvarrechi S, Phung LTK, Lee M, Bahadori A, et al. (2016) Phase equilibrium modelling of natural gas hydrate formation conditions using LSSVM approach. Petroleum Science and Technology 34(16): 1431-1438.

5. Eghtedaei R, Abdi-khanghah M, Najar BS, Baghban AJP (2017) Viscosity estimation of mixed oil using RBF-ANN approach. Petroleum Science and Technology 35(17): 1731-1736.

6. Peng J, Pan CJJ (2011) Particle swarm optimization RBF for gas emission prediction. Journal of Safety Science and Technology 7: 77-85.

7. Yunan I, Yassin IM, Adnan SFS, Rahiman MHF (2012) Identification of essential oil extraction system using Radial Basis Function (RBF) Neural Network. 2012 IEEE 8th International Colloquium on Signal Processing and its Applications, Malaysia.

8. Han HG, Lu W, Hou Y, Qiao JF (2018) An adaptivePSO-based self-organizing RBF neural network. IEEE Transactions on Neural Networks and Learning Systems 29(1): 104-117.

9. Mahanty R, Gupta PDJIPG (2004) Application of RBF neural network to fault classification and location in transmission lines. IEE Proceedings - Generation, Transmission and Distribution 151(2): 201-212.

10. Frapiccini E, Marini M (2015) Polycyclic aromatic hydrocarbon degradation and sorption parameters in coastal and open-sea sediment. Water, Air, and Soil Pollution 226: 246.

11. Olawoyin R (2016) Application of back propagation artificial neural network prediction model for the PAH bioremediation of polluted soil. Chemosphere 161: $145-150$.

12. Sayyad Amin J, Bahadori M, Lee M, Kashiwao T, Bahadori A, et al. (2016) Prediction of carbon dioxide separation from gas mixtures in petroleum industries using the Levenberg-Marquardt algorithm. Petroleum Science and Technology 34(8): 703-711.

13. Sayyad Amin J, Rajabi Kuyakhi H, Kashiwao T, Bahadori AJPS (2019) Development of ANFIS models for polycyclic aromatic hydrocarbons (PAHs) 


\section{Petroleum \& Petrochemical Engineering Journal}

formation in sea sediment. Petroleum Science and Technology 37(6): 679-686.

14. Baghban A, Kardani MN, Mohammadi AH (2018) Improved estimation of Cetane number of fatty acid methyl esters (FAMEs) based biodiesels using TLBONN and PSO-NN models. Fuel 232: 620-631.

15. Rajabi Kuyakhi H, Tahmasbi Boldaji R (2019) A novel ANFIS model to prediction of the density of $n$-alkane in different operational condition. Petroleum Science and Technology 37(24): 2429-2434.

16. Sayyad Amin J, Nikkhah S, Veiskarami M (2015) A statistical method for assessment of the existing correlations of hydrate forming conditions. Journal of Energy Chemistry 24(1): 93-100.
17. Sayyad Amin J, Alimohammadi S, Zendehboudi S (2017) Systematic investigation of asphaltene precipitation by experimental and reliable deterministic tools. The Canadian Journal of Chemical Engineering 95(7): 1388-1398.

18. Sayyad Amin J, Nikkhah S, Zendehboudi S (2017) A new experimental and modeling strategy to determine asphaltene precipitation in crude oil. Chemical Engineering Research and Design 128: 162173.

19. Sayyad Amin J, Rajabi Kuyakhi H, Bahadori A (2019) Prediction of formation of polycyclic aromatic hydrocarbon (PAHs) on sediment of Caspian Sea using artificial neural networks. Petroleum Science and Technology 37(18): 1987-2000. 